\title{
Effects of Short-Day and Gibberellic Acid Treatments on Summer Vegetative Propagation of Napier Grass (Pennisetum purpureum Schumach)
}

\author{
Yasuyuki Ishii, ${ }^{1}$ Asuka Yamano, ${ }^{2}$ and Sachiko Idota ${ }^{1}$ \\ ${ }^{1}$ Faculty of Agriculture, University of Miyazaki, Miyazaki 889-2192, Japan \\ ${ }^{2}$ Graduate School of Agriculture, University of Miyazaki, Miyazaki 889-2192, Japan \\ Correspondence should be addressed to Yasuyuki Ishii; yishii@cc.miyazaki-u.ac.jp
}

Received 1 March 2016; Accepted 16 June 2016

Academic Editor: Kent Burkey

Copyright ( $\odot 2016$ Yasuyuki Ishii et al. This is an open access article distributed under the Creative Commons Attribution License, which permits unrestricted use, distribution, and reproduction in any medium, provided the original work is properly cited.

\begin{abstract}
The effects of short-day $(\mathrm{SD})$ and gibberellic acid $\left(\mathrm{GA}_{3}\right)$ treatments on promoting vegetative propagation during the summer were examined in Napier grass (Pennisetum purpureum Schumach). A dwarf variety of late heading type (DL) Napier grass was exposed to three SD treatments $\left(5,10\right.$, and 20 short days plus a spray of $400 \mathrm{ppm} \mathrm{GA}_{3}$ solution following each SD treatment, GASD) or no treatment (control). Additionally, then, a dwarf variety of early heading (DE) and the normal variety of Merkeron (ME) were exposed to 10 days of GA-SD treatment together with nontreated controls. For DL and DE, GA-SD treatments showed the following effects: 10-day GA-SD treatment increased significantly $(P<0.05)$ the length of lateral tiller buds, maintained a high rooting percentage, and increased the diameter of the tiller buds. This resulted in a taller plant, one with enhanced tiller numbers, and thus a greater number of established nursery plants for the two dwarf varieties. In contrast, there was only a limited positive effect of the GA-SD treatments on the normal variety, ME. Thus, 10 days of GA-SD treatment was judged to be the most effective treatment for promoting lateral tiller bud elongation and early maturation in tiller buds for the two dwarf varieties of Napier grass.
\end{abstract}

\section{Introduction}

Napier grass (Pennisetum purpureum Schumach) belongs to a tropical $\mathrm{C}_{4}$ grass with high dry matter productivity $[1,2]$ and it can elongate its stem internode without phase transition from the vegetative to the reproductive state. Napier grass is now used for multiple purposes, including cut-and-carry fodder for herbivores [3], rotational grazing use [4], and feedstock for bioenergy production [5] and for phytoremediation [6] in the Kyushu area of Japan. Napier grass rarely produces viable seed and thus is commonly propagated vegetatively using stem cuttings and rooted tillers $[1,7,8]$. However, because protocols for efficient nursery production of Napier grass have not yet been established and a stable supply of nursery plants cannot be assured during all of the growing seasons, cultivation of this grass species remains limited mainly due to the shortage of nursery-grown rooted propagules [9].

In our previous study, although vegetative propagation of Napier grass was accomplished with cell-tray nursery plants $[10,11]$, the propagation season was strictly limited to the late autumn. It is difficult for these late-autumn propagated nursery plants to be transplanted in the field soon after propagation due to the frost damage. Thus, nursery plants needed to be maintained in the glasshouse over the wintering season.

Hare et al. [12] conducted short-day (SD) treatment on another tropical grass, Paspalum atratum, to induce the transition of growth stage to the reproductive phase, resulting in the heading and flowering in summer season, which is unusual since $P$. atratum normally never heads until late September, after being subjected to the naturally occurring 
SD photoperiod. It has been reported that tropical grasses have a suppressed vegetative growth in response to application of growth retardants [13]. Dwarf varieties of Napier grass are blocked in the pathway of gibberellin biosynthesis and thus exhibit severely suppressed stem elongation before the phase transition to the reproductive state [7]. Thus, it is considered as feasible that SD and/or $\mathrm{GA}_{3}$ treatments could elongate the stem internode [14-17], which may facilitate the successful vegetative propagation and production of nursery plants for dwarf Napier grass.

The aim of the present study, therefore, was to determine the optimal length of SD and $\mathrm{GA}_{3}$ treatments in dwarf Napier grass (Experiment 1) and also difference of Napier grass in SD and GA treatments (Experiment 2) on the effect of the nursery propagation in the summer.

\section{Materials and Methods}

2.1. Optimal Growth Stages of $S D$ and $G A_{3}$ Treatments (Experiment 1). The experiment was conducted at the University of Miyazaki in southern Kyushu, Japan $\left(31.83^{\circ} \mathrm{N}\right.$ and $131.41^{\circ} \mathrm{E}, 22 \mathrm{~m}$ asl) from 2 July 2010 to 16 November 2010 . The aboveground stems in the dwarf variety of late heading type (DL) Napier grass, which was overwintered in a glasshouse from December 2009 to April 2010, were cut into single-node stem cuttings and transplanted into a cell tray (36 cells and $4 \times 4 \times 4 \mathrm{~cm}$ depth/cell), filled with "raising seedling" medium (Takii Co. Ltd., Kyoto) on 4 May 2010. After emergence of tillers, the cell tray was fertilized with a chemical fertilizer (14(\%): $14(\%): 14(\%)$ in $\mathrm{N}, \mathrm{P}_{2} \mathrm{O}_{5}$, and $\mathrm{K}_{2} \mathrm{O}$, resp.) at $2 \mathrm{~g}$ per cell tray on 9 June, 22 June, and 17 July, respectively. Cell-tray DL Napier grass plants were irrigated as required and thinned to one main shoot only for each cell at the start of treatment.

Treatments were applied in a split plot design with 3 replications under 3 levels of SD, namely, 5, 10, and 20 days, combined with and without foliar spray of $400 \mathrm{ppm}$ $\mathrm{GA}_{3}$ solution and surfactant (HitenPower, Hokko Chemical Industry, Co., Ltd., Tokyo, $0.1 \%$ v/v), which was determined to be the most effective concentration in preliminary experiments with the DL variety of Napier grass, at the start of treatments (designated as GA-SD and SD). Plants designated as controls $(C)$ were grown under natural LD and received no GA-SD or SD treatment. The SD treatment was conducted by setting cell trays of DL Napier grasses into a plastic tunnel at $1.75 \mathrm{~m}$ height and $0.5 \mathrm{~m}$ base diameter with ventilation by an air pump at $2 \mathrm{~L} / \mathrm{min}$ to reduce overheating of the inside temperature. The tunnel was shaded with black cloth for about $14 \mathrm{~h}$, thus giving a $10 \mathrm{~h} \mathrm{SD}$. Initially, three lengths of SD were utilized, 5, 10, and 20 days, starting on 12 July 2010. The natural day length when the SD treatments were imposed ranged from $13 \mathrm{~h} 43 \mathrm{mins}$ to $14 \mathrm{~h} 6$ mins.

Height of the node where the uppermost expanded leaf was attached was measured 5 days before treatment and 0,2 , and 5 weeks after treatment for 4 plants (shoots) per replication within each of the cell trays. At 5 weeks after treatment, internode length and length, diameter, and rooting of lateral tiller buds were determined from the bottom to the uppermost expanded leaf nodal position. However, immature stem nodes with less than $10 \mathrm{~mm}$ of internode length were omitted from the observation due to the likelihood of poor vegetative propagation. After these measurements each shoot was cut into the single-node cuttings, which were transplanted into the cell tray in the same size as mentioned before, incubated for 4 weeks outside under natural (long) day lengths, and fertilized with $0.33 \mathrm{~L}$ per cell tray of a $1 / 500$ Hyponex solution, containing 6(\%), 10(\%), and 5(\%) of $\mathrm{N}$, $\mathrm{P}_{2} \mathrm{O}_{5}$, and $\mathrm{K}_{2} \mathrm{O}$, respectively, at 3 weeks after transplanting. At the end of 4-week cell culture, rooted stem cuttings were transplanted to the Andosols (soils of active volcanic areas) at $10 \mathrm{~cm} \times 20 \mathrm{~cm}$ of intrarow and interrow spacing, respectively, and fertilized at $5 \mathrm{~g} / \mathrm{m}^{2}$, each of $\mathrm{N}, \mathrm{P}_{2} \mathrm{O}_{5}$, and $\mathrm{K}_{2} \mathrm{O}$, respectively, using the chemical fertilizer. On 16 November 2010 , that is, 8,7 , and 6 weeks after the termination of 5,10 , and 20 days of SD treatments, respectively, the percentage of fully established plants was determined, and plant height and lateral tiller number for the DL Napier grass were measured for all vegetative (not flowering) nursery plants.

\subsection{Varietal Differences in SD and GA Treatments} (Experiment 2). The experiment was also conducted at the University of Miyazaki from 26 March 2011 to 22 October 2011. Varieties utilized were DL, another dwarf variety which was an early heading type (DE) and a normal (tall) variety of Merkeron (ME). Single-node cuttings were obtained from the overwintered plants in the glasshouse on 26 March 2011 for ME and on 21 April 2011 for DL and DE. These cuttings were transplanted into cell tray of the same size as in Experiment 1 and incubated outside. Fertilizer was supplied by $0.33 \mathrm{~L}$ of a $1 / 500$ diluted Hyponex solution per cell tray on 26 April and additionally with $5 \mathrm{~g}$ of chemical fertilizer per cell tray on both 7 June and 5 July 2011 for ME and on 18 May, 7 June, and 5 July, each for DL and DE. Cell-tray Napier grasses were irrigated as required and thinned to one main shoot only for each cell at the start of treatment.

Treatments were applied in a split plot design with 3 replications under 10 days of SD treatments for 14 hours of dark condition, combined with foliar spray of 400 ppm $\mathrm{GA}_{3}$ solution at the start of treatments (designated as GA-SD), and started on 5 July 2011. The natural day length when the SD treatments were imposed was ranging from $14 \mathrm{hr} 4 \mathrm{mins}$ to $14 \mathrm{hr} 9$ mins. No treatment of GA-SD was applied to Napier grass plants which were designated as control (C). Heights were measured as detailed for Experiment 1 (above). At 5 weeks after treatment on 23 August 2011, internode length and the length, diameter, rooting of tiller buds, and rooting of stem nodes were determined. Heights were measured from the soil surface to the uppermost expanded leaf node position. After making these measurements, each shoot was cut into the single-node cuttings, which were transplanted into the cell tray, incubated for 2 weeks outside, and fertilized with $0.33 \mathrm{~L}$ per cell tray of a 1/500 diluted Hyponex solution at 1 week after transplanting on 30 August 2011. Nursery plants with leaves were counted and transplanted to the Andosols at $15 \mathrm{~cm}$ and $25 \mathrm{~cm}$ of intrarow and interrow spacing, respectively, on 13 September 2011. 


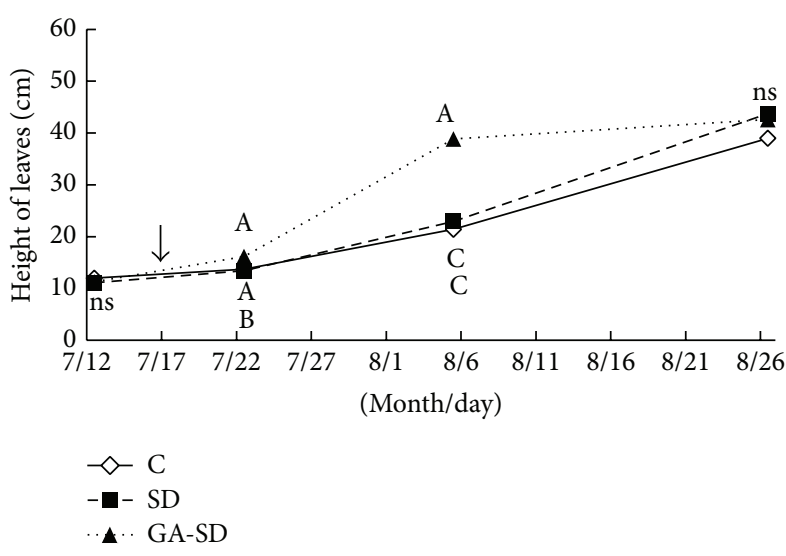

(a) 5-day treatment

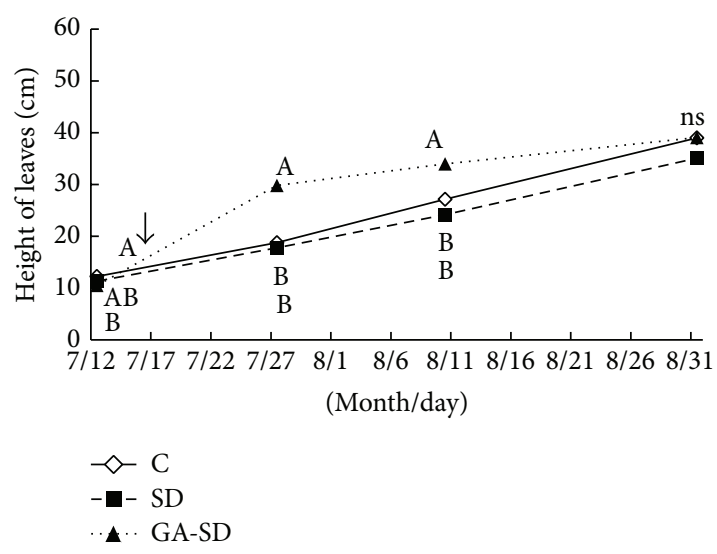

(b) 10-day treatment

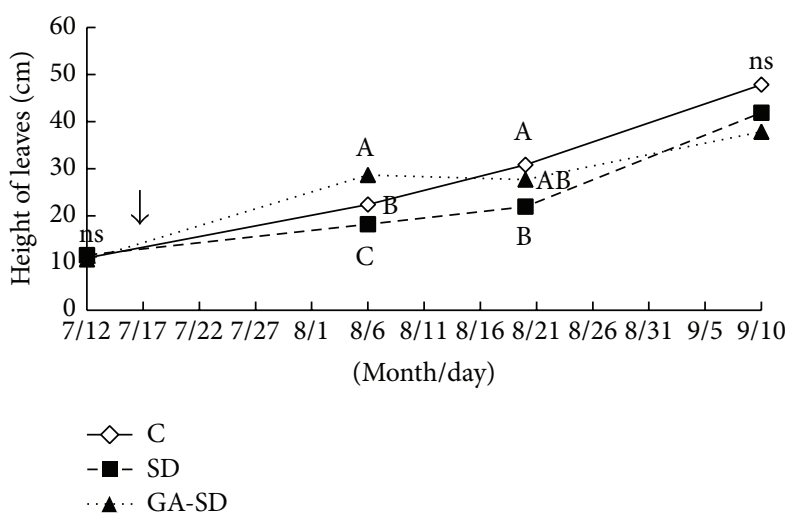

(c) 20-day treatment

Figure 1: Changes in height of the uppermost expanded leaves in dwarf (DL) Napier grass for 5 weeks after treatment (Exp. 1). Treatment: control (C), short-day (SD), and foliar spray of gibberellin acid $\left(\mathrm{GA}_{3}\right)$, followed by SD (GA-SD). An arrow indicates the date of the start of treatment. Figures with different letters indicate the significant difference at the same date by the Bonferroni test at the $5 \%$ level.

2.3. Statistical Analysis. For both experiments, Student's $t$ test and one-way analysis of variance (ANOVA) for a split plot design were performed using software (Excel statistics 2010). Mean separations were tested using the Bonferroni method at the $5 \%$ level of probability.

\section{Results}

3.1. Optimal Growth Stages of SD and GA Treatments (Experiment 1). Height of the uppermost expanded leaf node was significantly higher in GA-SD than in SD and C plots irrespective of SD treatment periods at 1 and 2 weeks after treatment. The height increased gradually with time for plants given SD treatment (Figure 1). However, 20-day SD treatment tended to retard the stem elongation at 5 weeks after treatment, relative to control plants.

Internode length and length, diameter, and rooting of tiller buds showed a significant effect of GA-SD and/or SD treatments for all of 5, 10, and 20 days of treatment periods at $5 \%$ level (Table 1). Length, diameter, and rooting of tiller buds were significantly higher in 5 and 10 days of GA-SD treatments than in control and the degree of enhancement was larger for the 10-day treatment than the 5-day treatment. Effect of treatments was determined in each nodal position under the 10-day long SD treatment, which was the most effective SD treatment (Figure 2). The GA-SD treatments significantly increased the internode length at the 3rd node, tiller bud length at the 1st to the 5 th nodes, tiller bud diameter at the 3rd node, and tiller bud rooting at the 1st node, all relative to the control plants and also relative to the SD plants. The SD treatments plants had increased internode lengths at the 1st to the 3 rd nodal positions and tiller bud lengths at the 8th node, relative to the control plants.

Established percentage of stem cuttings with rooted tiller buds achieved more than $80 \%$ among all the treatments. Five days of GA-SD treatment increased the plant height of nursery plants and 10 days of GA-SD treatment increased both plant height and tiller number of nursery plants, compared with control (Figure 3).

3.2. Varietal Differences in Responses to SD and GA Treatments (Experiment 2). Height of the uppermost expanded leaf 
TABLE 1: Effect of treatment and nodal position on nursery plant attributes in dwarf (DL) Napier grass (Exp. 1).

(a) 5-day treatment

Plant attribute

Internode length (mm) Tiller bud length (mm) Tiller bud diameter (mm) Rooting (\%)

\begin{tabular}{lcccc}
\hline Treatment & $\mathrm{ns}$ & $* *$ & $* *$ & $* *$ \\
Nodal position & $* *$ & $* *$ & $* *$ & $* *$ \\
Interaction of treatment $\times$ nodal position & $* *$ & $8.28^{\mathrm{b}}$ & $3.24^{\mathrm{b}}$ & $0.00^{\mathrm{b}}$ \\
\hline $\mathrm{C}$ & 28.64 & $8.54^{\mathrm{b}}$ & $3.31^{\mathrm{ab}}$ & $0.00^{\mathrm{b}}$ \\
SD & 32.73 & $15.27^{\mathrm{a}}$ & $4.02^{\mathrm{a}}$ & $6.25^{\mathrm{a}}$ \\
GA-SD & 35.48 & &
\end{tabular}

(b) 10-day treatment

\begin{tabular}{|c|c|c|c|c|}
\hline & \multicolumn{4}{|c|}{ Plant attribute } \\
\hline & Internode length $(\mathrm{mm})$ & Tiller bud length $(\mathrm{mm})$ & Tiller bud diameter $(\mathrm{mm})$ & Rooting (\%) \\
\hline Treatment & ns & $* *$ & $* *$ & $* *$ \\
\hline Nodal position & $* *$ & $* *$ & $* *$ & $* *$ \\
\hline Interaction of treatment $\times$ nodal position & $* *$ & $* *$ & ns & $* *$ \\
\hline $\mathrm{C}$ & 28.12 & $7.40^{\mathrm{c}}$ & $3.27^{\mathrm{b}}$ & $0.00^{\mathrm{b}}$ \\
\hline $\mathrm{SD}$ & 31.10 & $8.67^{\mathrm{b}}$ & $3.88^{\mathrm{ab}}$ & $1.85^{\mathrm{b}}$ \\
\hline GA-SD & 28.09 & $12.89^{\mathrm{a}}$ & $4.13^{\mathrm{a}}$ & $9.26^{\mathrm{a}}$ \\
\hline
\end{tabular}

(c) 20-day treatment

Plant attribute

\begin{tabular}{|c|c|c|c|c|}
\hline & \multicolumn{4}{|c|}{ Plant attribute } \\
\hline & Internode length $(\mathrm{mm})$ & Tiller bud length (mm) & Tiller bud diameter (mm) & Rooting (\%) \\
\hline Treatment & ** & ** & ** & ns \\
\hline Nodal position & ** & * & ** & * \\
\hline Interaction of treatment $\times$ nodal position & $* *$ & $* *$ & ns & $* *$ \\
\hline $\mathrm{C}$ & $31.97^{\mathrm{a}}$ & $9.69^{\mathrm{a}}$ & $3.57^{\mathrm{a}}$ & 2.27 \\
\hline SD & $27.35^{\mathrm{ab}}$ & $8.48^{\mathrm{ab}}$ & $3.06^{\mathrm{b}}$ & 0.00 \\
\hline GA-SD & $21.27^{\mathrm{b}}$ & $8.44^{\mathrm{b}}$ & $2.93^{\mathrm{b}}$ & 0.00 \\
\hline
\end{tabular}

${ }^{*} P<0.05,{ }^{* *} P<0.01$, and ${ }^{\mathrm{ns}} P>0.05$.

Values with different letters indicate the significant difference by the Bonferroni test at the $5 \%$ level.

node was significantly higher in GA-SD treatment than in $\mathrm{C}$ plots at 1 week after treatment and thereafter across all varieties. Heights were 26, 40, and $19 \mathrm{~cm}$ higher than the control for DL, DE, and ME, respectively (Figure 4).

Internode length and length, diameter, and rooting from stems showed significant effect of GA-SD treatments for almost all the examined varieties at 5\% level (Table 2), except for several nonsignificant effects (Table 2). Internode length and tiller bud length in GA-SD treatment were significantly higher than those in the control for DL and DE, and the enhancement was more effective in DE than in DL. In addition, tiller bud diameter in DL, stem rooting in $\mathrm{DE}$, and internode length in ME were significantly higher in the GASD treatment, compared with the control.
Effect of treatments was measured in each nodal position in the most responsive variety of DE (Figure 5). The internode length at the 4 th to 7 th nodes, the tiller bud length at the 3 rd to 7 th nodes, the tiller bud diameter at the 3 rd to 4 th nodes, and stem rooting at the 4 th to 6 th nodes were significantly higher in the GA-SD treatment than in the control. It is shown that the positively promoted effects on tiller bud maturation appeared at the central to the upper nodal positions (Figure 5).

Established percentage of stem cuttings with leaved tiller buds showed more than 95\% across all the varieties and treatments, except for the GA-SD treatment in ME where it was at $85.3 \%$. No significant differences in plant height and tiller number were detected in any variety (Figure 6). 


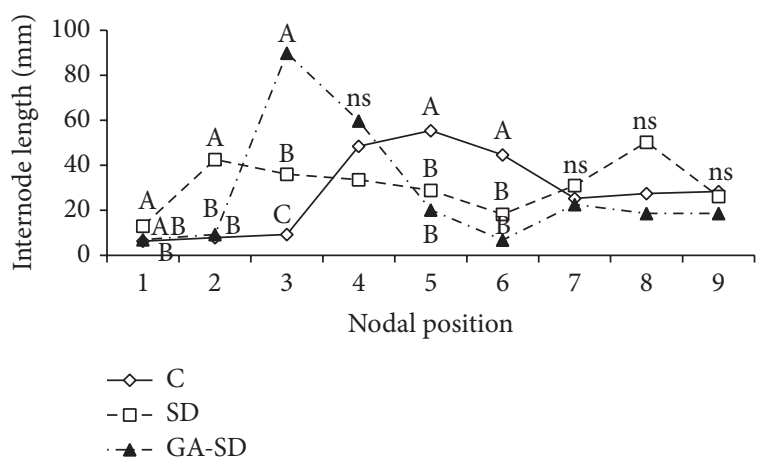

(a)

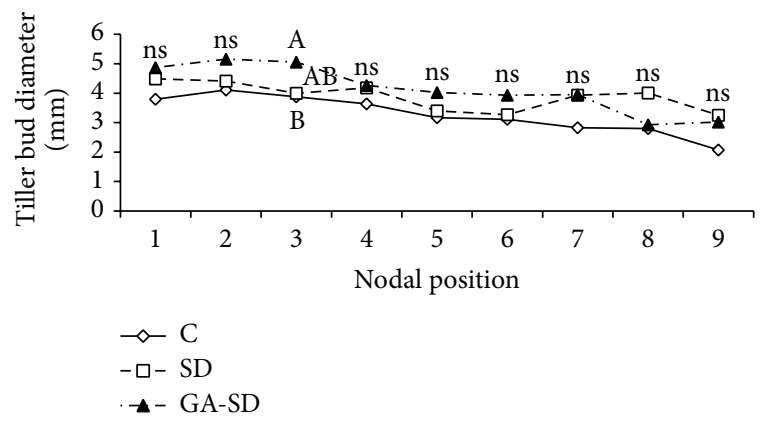

(c)

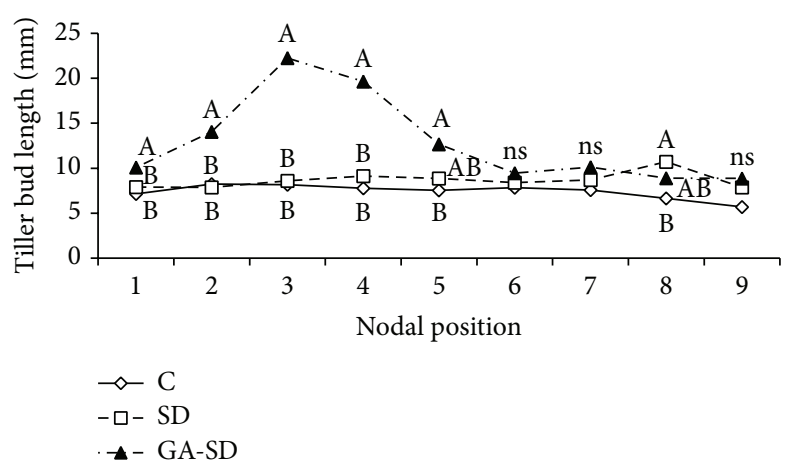

(b)

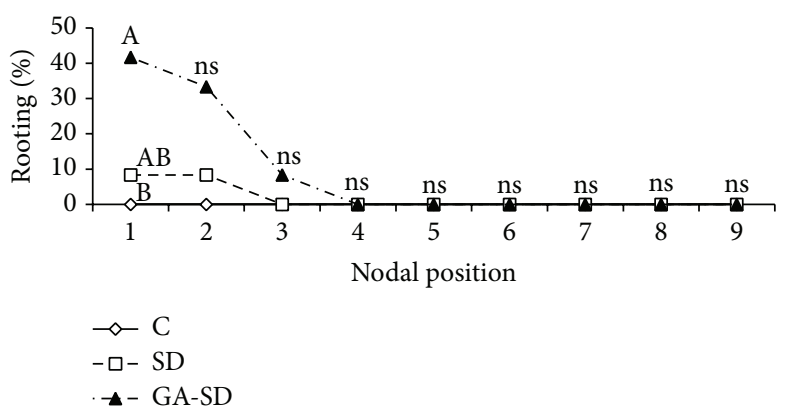

(d)

FiguRE 2: Changes in plant attributes of internode length (a), tiller bud length (b), tiller bud diameter (c), and tiller bud rooting (d) among nodal positions in dwarf (DL) Napier grass, subjected to 10-day treatment (Exp. 1). Nodal position was counted from the bottom of shoots. For treatments, refer to Figure 1. Figures with different letters indicate the significant difference at the same nodal position by the Bonferroni test at the $5 \%$ level.

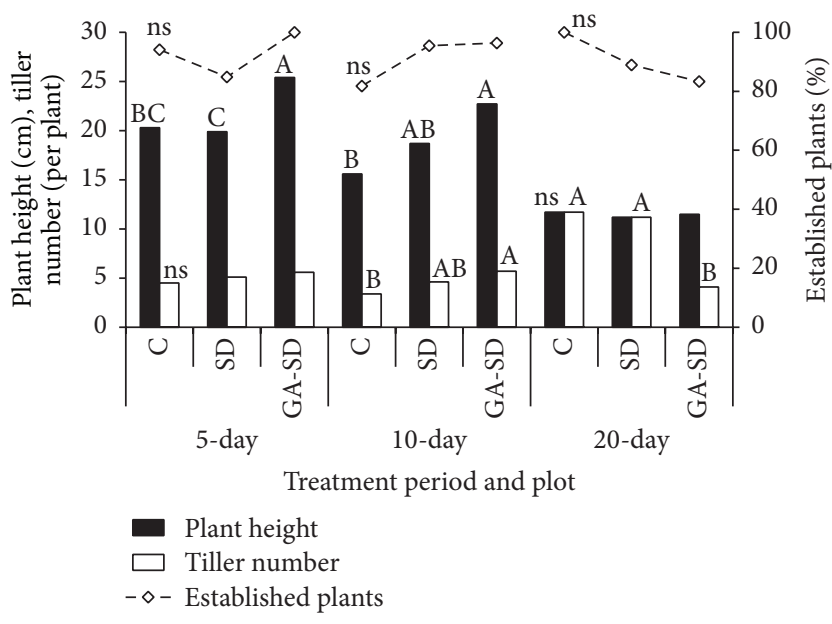

FIGURE 3: Plant growth attributes in transplanted regrowth plants after treatments in dwarf (DL) Napier grass (Exp. 1). For treatments, refer to Figure 1. Figures with different letters indicate the significant difference at the same date by the Bonferroni test at the $5 \%$ level.

\section{Discussion}

Height of the uppermost expanded leaf node in DL reached $30 \mathrm{~cm}$ in late July for the 10-day GA-SD treatment and in early
August for the 5-day GA-SD treatment, compared with late August in the control plot. This may be brought about by two factors; the first was due to the rapid enhancement of stem elongation in the basal several stem nodes by the foliar $\mathrm{GA}_{3}$ spray [18] as shown in Figures 1 and 2. The second was due to the gradual enhancement of stem elongation by SD treatment $[14,17]$. Therefore, $\mathrm{GA}_{3}$ treatment showed the rapid effect and SD treatment showed gradual effect on stem elongation in DL Napier grass. Vegetative nursery propagation of Napier grass requires the use of the single nodal stem cuttings and thus the stem elongation in the dwarf varieties is essential for saving labor time and costs in vegetative propagation. In the present study, both the 5-day and 10-day GA-SD treatments were demonstrated as being effective treatments in vegetative propagation by enhancing stem elongation in the early summer season.

In Experiment 2, the 10-day GA-SD treatment induced a similar enhancement of stem elongation by about one month across the three varieties of Napier grass. Therefore, 10-day GA-SD treatment allows for significant promotion of stem elongation early in the summer season.

The SD and GA-SD treatments increased almost all of the growth attributes effective for the vegetative propagation and the additive positive effect of GA-SD treatment makes it a preferred treatment, relative to SD only treatments for 5 days 


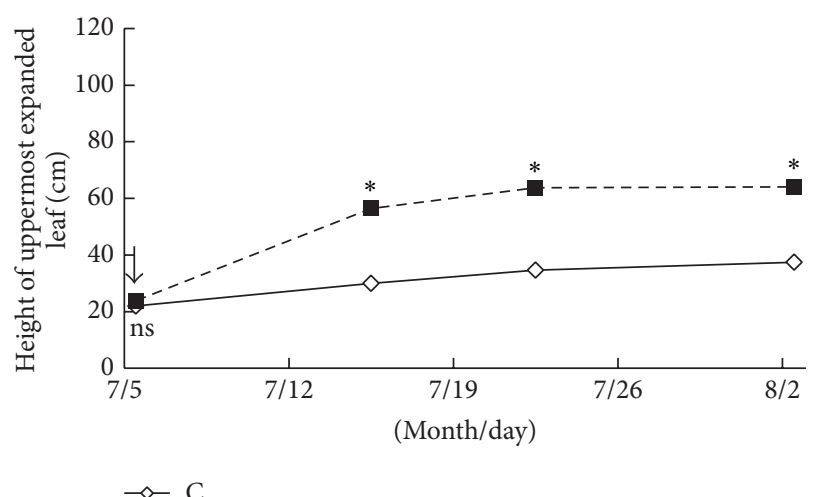

$\leadsto$ C

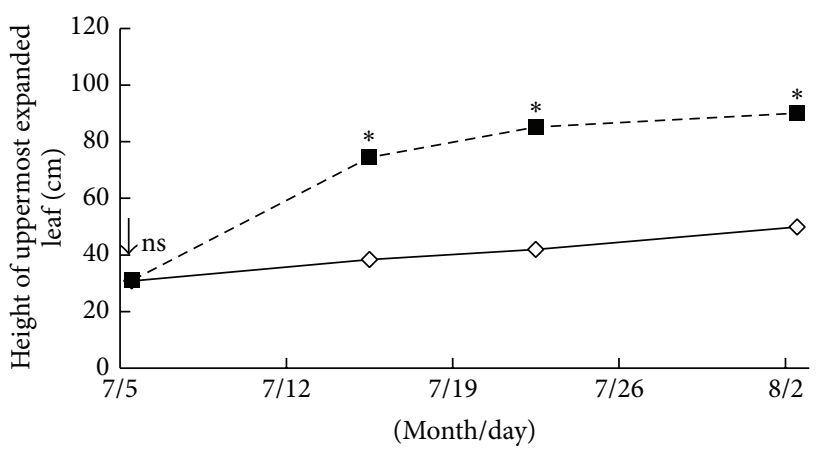

$\leadsto C$

(a) $\mathrm{DL}$

(b) $\mathrm{DE}$

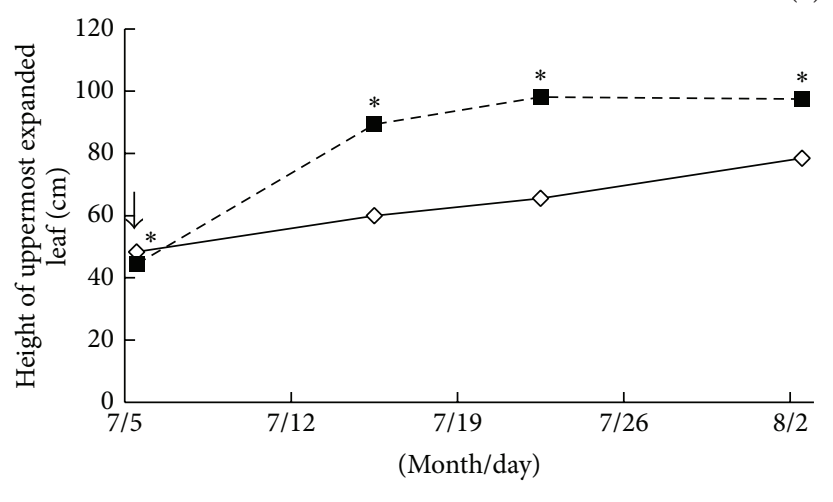

$\neg C$

- - GA-SD

(c) $\mathrm{ME}$

Figure 4: Changes in height of the uppermost expanded leaves in 3 varieties of Napier grass for 5 weeks after treatment (Exp. 2). Variety: dwarf-late heading type (DL), dwarf-early heading type (DE), and Merkeron (ME). Treatment: control (C) and foliar spray of gibberellin acid $\left(\mathrm{GA}_{3}\right)$, followed by SD (GA-SD). An arrow indicates the date of the start of treatments. ${ }^{*} P<0.05$ and ${ }^{\mathrm{ns}} P>0.05$.

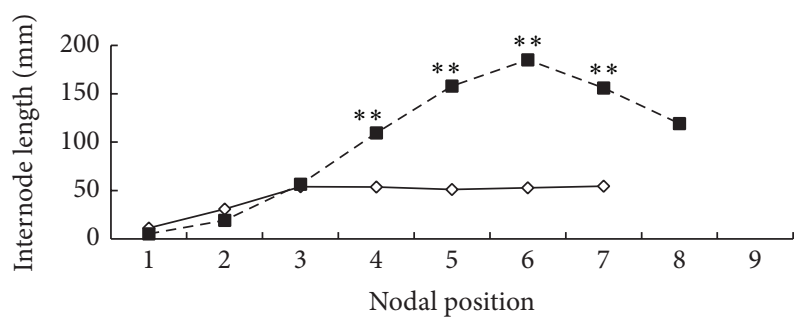

$\leadsto C$

- - GA-SD

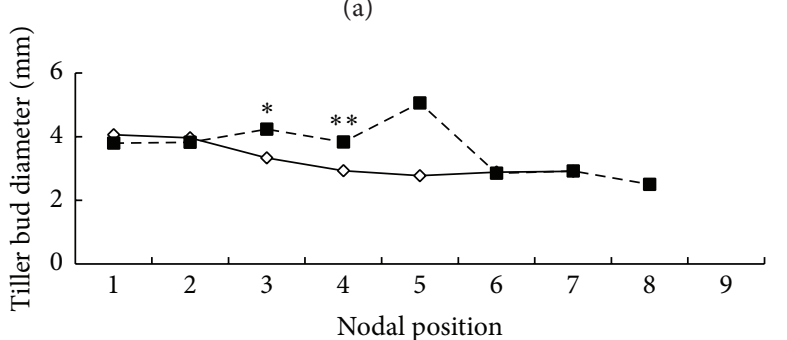

$\multimap C$

- - GA-SD

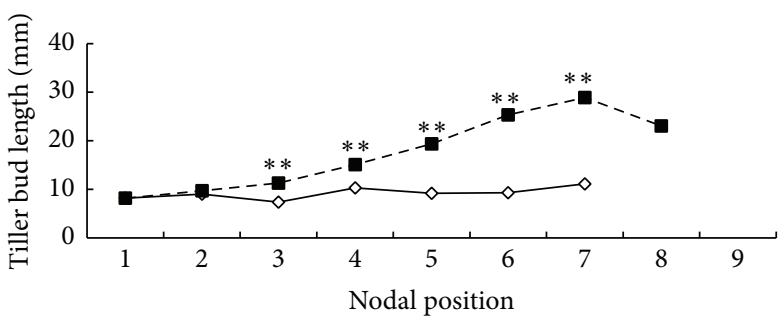

$\leadsto C$

- - GA-SD

(b)

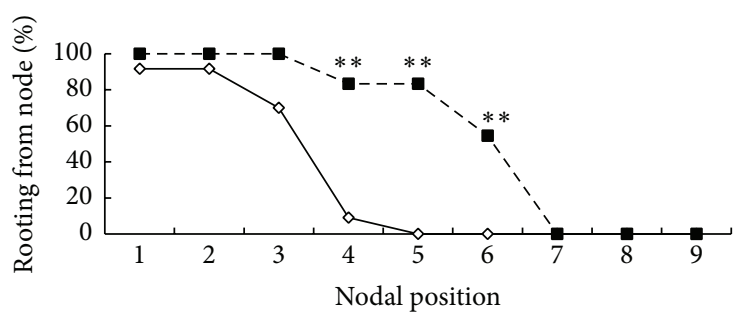

$\leadsto C$

- - GA-SD

(c)

(d)

FIGURE 5: Changes in plant attributes of internode length (a), tiller bud length (b), tiller bud diameter (c), and rooting from nodes (d) among nodal positions in dwarf (DE) Napier grass, subjected to 10-day treatment (Exp. 2). Nodal position was counted from the bottom of shoots. For treatments, refer to Figure $4 .{ }^{*} P<0.05$ and ${ }^{* *} P<0.01$. 
TABLE 2: Effect of treatment and nodal position on nursery plant attributes in three varieties of Napier grass (Exp. 2).

(a) Variety DL

Plant attribute

Internode length (mm) Tiller bud length (mm) Tiller bud diameter (mm) Rooting (\%)

\begin{tabular}{|c|c|c|c|c|}
\hline Treatment & ** & ** & * & ns \\
\hline Nodal position & ** & ** & ns & $* *$ \\
\hline Interaction of treatment $\times$ nodal position & $* *$ & $* *$ & ns & ns \\
\hline $\mathrm{C}$ & 33.56 & 8.39 & 3.26 & 13.55 \\
\hline GA-SD & $65.65^{* *}$ & $14.45^{* *}$ & $3.55^{*}$ & 24.07 \\
\hline
\end{tabular}

(b) Variety DE

Plant attribute

Internode length (mm) Tiller bud length (mm) Tiller bud diameter (mm) Rooting (\%)

\begin{tabular}{|c|c|c|c|c|}
\hline Treatment & ** & ** & ns & $* *$ \\
\hline Nodal position & ** & ** & ns & $* *$ \\
\hline Interaction of treatment $\times$ nodal position & $* *$ & $* *$ & ns & $* *$ \\
\hline $\mathrm{C}$ & 44.03 & 9.22 & 3.26 & 29.16 \\
\hline GA-SD & $101.11^{* *}$ & $17.62^{* *}$ & 3.63 & $57.91^{* *}$ \\
\hline
\end{tabular}

(c) Variety ME

Plant attribute

Internode length (mm) Tiller bud length $(\mathrm{mm}) \quad$ Tiller bud diameter $(\mathrm{mm}) \quad$ Rooting (\%)

\begin{tabular}{|c|c|c|c|c|}
\hline Treatment & $* *$ & ns & $* *$ & ns \\
\hline Nodal position & $* *$ & $* *$ & $* *$ & $* *$ \\
\hline Interaction of treatment $\times$ nodal position & $* *$ & $* *$ & $\mathrm{~ns}$ & ns \\
\hline $\mathrm{C}$ & 61.88 & 12.12 & $4.45^{* *}$ & 53.79 \\
\hline GA-SD & $95.34^{* *}$ & 15.05 & 3.89 & 50.68 \\
\hline
\end{tabular}

${ }^{*} P<0.05,{ }^{* *} P<0.01$, and ${ }^{\mathrm{ns}} P>0.05$.

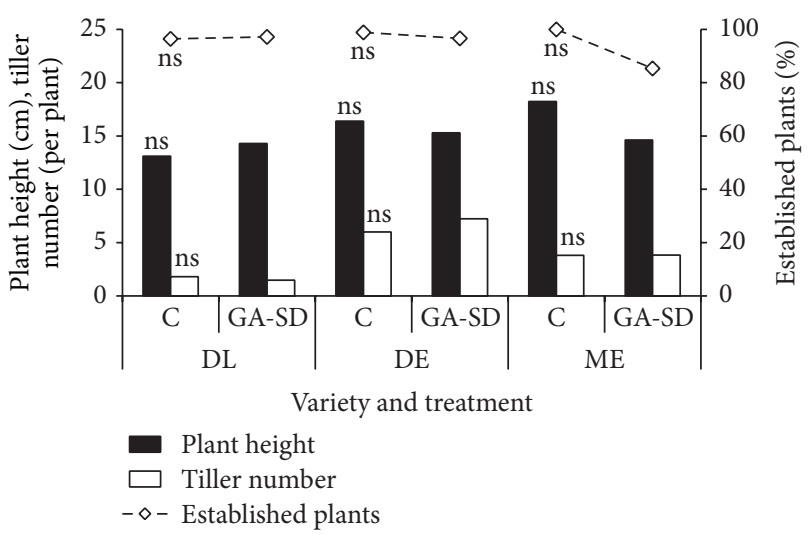

Figure 6: Plant growth attributes in transplanted regrowth plants after treatments of 3 Napier grass varieties (Exp. 2). For variety and treatment, refer to Figure $4 .{ }^{\text {ns }} P>0.05$.

and 10 days (Tables $1(\mathrm{a})$ and $1(\mathrm{~b})$ ). The 20-day long treatment suppressed positive effects of shorter length (5-day and 10-day long SD and GA-SD treatments) (Table 1(c)).
In Experiment 2, the 10-day GASD treatment is the most effective in increasing the internode length, length and diameter of tiller buds, and stem rooting to enhance maturation of tiller buds and facilitate the emergence of tiller buds after transplanting to the field, which enables maintaining the enough biomass for overwintering before below-freezing temperatures occur [19].

Ito et al. [13] demonstrated that the foliar spray of growth retardant regulator of paclobutrazol to $\mathrm{ME}$ decreased the height of the uppermost expanded leaf node significantly and the suppression of plant growth continued for 2 months after the treatment. The suppressing effect on the growth attributes appeared at the lowest stem nodal position for internode length, followed by leaf sheath length and the leaf length and width at the higher nodal positions [13]. In Experiment 1, the 10 -day GA-SD treatment promoted the internode length at the 3rd to 4 th nodal positions, while length, diameter, and rooting of tiller buds tended to be promoted at the 1st to the 3 rd or 4 th nodal positions. In Experiment 2, DE showed the promoting effect on the internode length and stem rooting at the 4 th to 7 th nodal positions, while length and diameter of 
tiller buds increased from the 3rd nodal positions. Therefore, in both Experiments 1 and 2, growth attributes of tiller buds, which are considered as the next generation once they form roots, were significantly affected by the treatments in their lower nodal positions, a finding which is consistent with the growth retardant effect on the normal variety of ME [13].

However, GA-SD treatment in the normal variety of $\mathrm{ME}$ promoted stem elongation much more compared to dwarf varieties of DL and DE. In doing so, the GA-SD treatment led to excessively succulent growth in $\mathrm{ME}$, which suffered badly from lodging, breakage of stems, and insect damage, events which were quite rare in the control ME plants. It will thus be necessary to determine whether there is an optimal dose of foliar $\mathrm{GA}_{3}$ spray to the normal variety (ME) of Napier grass.

In conclusion, the most effective treatment for promoting maturity of tiller buds and establishment of nursery plants in the field is the 10-day GA-SD treatment, which was suitable for dwarf varieties DL and DE; that is, it increased internode length and tiller bud length, thereby reducing labor time and cost for vegetative propagation.

\section{Competing Interests}

The authors declare that there are no competing interests regarding the publication of this paper.

\section{References}

[1] W. R. Ocumpaugh and L. E. Sollenberger, "Elephantgrass," in Forages Volume 1: An Introduction to Grassland Agriculture, R. F. Barns, D. A. Miller, and C. J. Nelson, Eds., pp. 443-445, Iowa State University Press, Ames, Iowa, USA, 1995.

[2] M. J. Williams and W. W. Hanna, "Performance and nutritive quality of dwarf and semi-dwarf elephantgrass genotypes in the south-eastern USA," Tropical Grassands, vol. 29, no. 2, pp. 122123, 1995.

[3] C. J. Chaparro and L. E. Sollenberger, "Nutritive value of clipped 'Mott' elephantgrass herbage," Agronomy Journal, vol. 89, no. 5, pp. 789-793, 1997.

[4] L. E. Sollenberger, G. M. Prine, W. R. Ocumpaugh, S. C. Schank, R. S. Kalmbacher, and C. S. Jones, "Dwarf napiergrass: a high quality forage with potential in Florida and the tropics," Soil and Crop Science Society of Florida Proceedings, vol. 46, no. 1, pp. 4246, 1987.

[5] C.-I. Na, L. E. Sollenberger, J. E. Erickson, K. R. Woodard, J. M. B. Vendramini, and M. L. Silveira, "Management of perennial warm-season bioenergy grasses. i. biomass harvested, nutrient removal, and persistence responses of elephantgrass and energycane to harvest frequency and timing," Bioenergy Research, vol. 8, no. 2, pp. 581-589, 2015.

[6] Y. Ishii, K. Hamano, D.-J. Kang, S. Idota, and A. Nishiwaki, "Cadmium phytoremediation potential of napiergrass cultivated in Kyushu, Japan," Applied and Environmental Soil Science, vol. 2015, Article ID 756270, 6 pages, 2015.

[7] L. E. Sollenberger, G. M. Prine, W. R. Ocumpaugh et al., Mott' Dwarf Elephantgrass: A High Quality Forage for the Subtropics and Tropics, Circular S-356, Agricultural Experiment Station, Institute of Food and Agricultural Sciences, University of Florida, Gainsville, Fla, USA, 1988.
[8] W. W. Hanna and L. E. Sollenberger, "Tropical and subtropical grasses," in Forages Volume II, The Science of Grassland Agriculture, R. F. Barner, C. J. Nelson, K. J. Moore, and M. Collons, Eds., pp. 245-255, Blackwell, Ames, Iowa, USA, 2007.

[9] T. Kipnis and S. Bnei-Moshe, "Improved vegetative propagation of napiergrass and pearl millet $\times$ napiergrass interspecific hybrids," Tropical Agriculture (Trinidad), vol. 65, no. 3, pp. 158$160,1988$.

[10] A. Yamano, Y. Ishii, K. Mori, R. F. Utamy, and S. Idota, "Effect of density of mother plants on efficiency of nursery production in dwarf napiergrass (Pennisetum purpureum Schumach)," in Proceedings of the 7th Asian Crop Science Association Conference, pp. 345-348, Bogor, Indonesia, September 2011.

[11] R. F. Utamy, Y. Ishii, L. Khairani, S. Idota, and K. Fukuyama, "Development of mechanical methods for cell-tray propagation and field transplanting of dwarf napiergrass (Pennisetum purpureum Schumach)," Journal of Agriculture and Rural Development in the Tropics and Subtropics, vol. 117, no. 1, pp. 11-19, 2015.

[12] M. D. Hare, K. Wongpichet, M. Saengkham, K. Thummasaeng, and W. Suriyajantratong, "Juvenility and long-short day requirement in relation to flowering of Paspalum atratum in Thailand," Tropical Grasslands, vol. 35, no. 2, pp. 139-143, 2001.

[13] K. Ito, Y. Ishii, M. Misumi, and H. Iwakiri, "Studies on the dry matter production of napiergrass. VI. Effect of a plant growth retardant, paclobutrazol on growth and dry matter of shoots," Japanese Journal of Crop Science, vol. 59, no. 3, pp. 469-474, 1990.

[14] P. Yañez, S. Chinone, R. Hirohata, H. Ohno, and K. Ohkawa, "Effects of time and duration of short-day treatments under long-day conditions on flowering of a quantitative short-day sunflower (Helianthus annuus L.) 'Sunrich Orange,' Scientia Horticulturae, vol. 140, pp. 8-11, 2012.

[15] V. Jokela, P. Virkajärvi, J. Tanskanen, and M. M. Seppänen, "Vernalization, gibberellic acid and photo period are important signals of yield formation in timothy (Phleum pratense)," Physiologia Plantarum, vol. 152, no. 1, pp. 152-163, 2014.

[16] R. W. King, L. N. Mander, T. Asp, C. P. MacMillan, C. A. Blundell, and L. T. Evans, "Selective deactivation of gibberellins below the shoot apex is critical to flowering but not to stem elongation of Lolium," Molecular Plant, vol. 1, no. 2, pp. 295-307, 2008.

[17] M. Talon and J. A. D. Zeevaart, "Stem elongation and changes in the levels of gibberellins in shoot tips induced by differential photoperiodic treatments in the long-day plant Silene armeria," Planta, vol. 188, no. 4, pp. 457-461, 1992.

[18] C. Matthew, W. A. Hofmann, and M. A. Osborne, "Pasture response to gibberellins: a review and recommendations," New Zealand Journal of Agricultural Research, vol. 52, no. 2, pp. 213225, 2009.

[19] Y. Ishii, K. Ito, and H. Numaguchi, "Effects of cutting date and cutting height before overwintering on the spring regrowth of summer-planted napiergrass (Pennisetum purpureum Schumach)," Journal of Japanese Grassland Science, vol. 40, no. 4, pp. 396-409, 1995. 


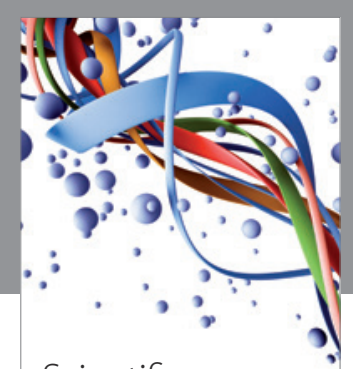

Scientifica
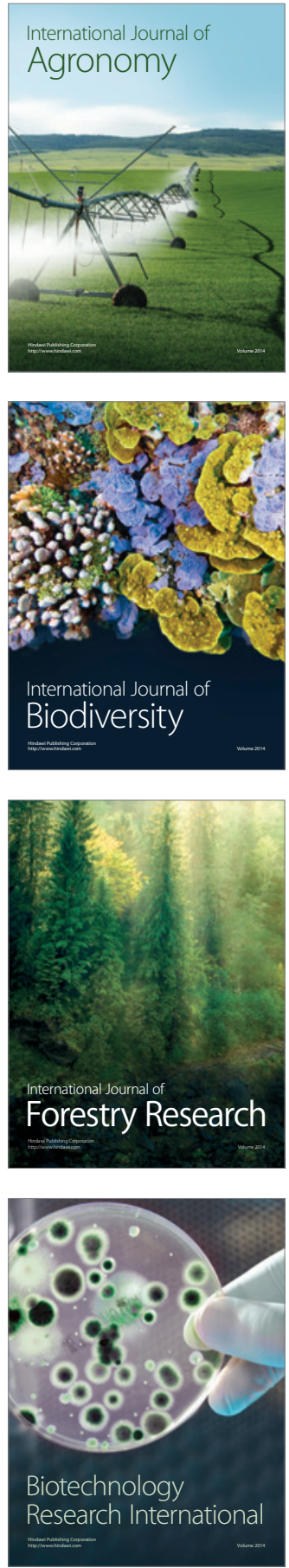
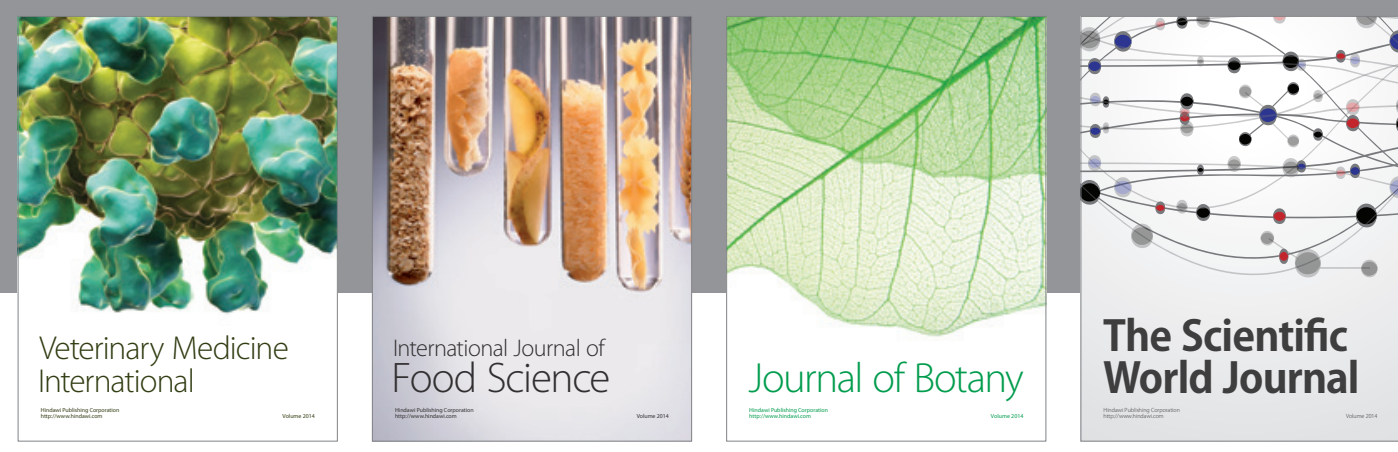

The Scientific

\section{World Journal}

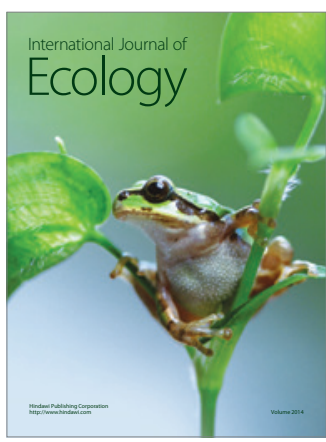

\section{Hindawi}

Submit your manuscripts at

http://www.hindawi.com
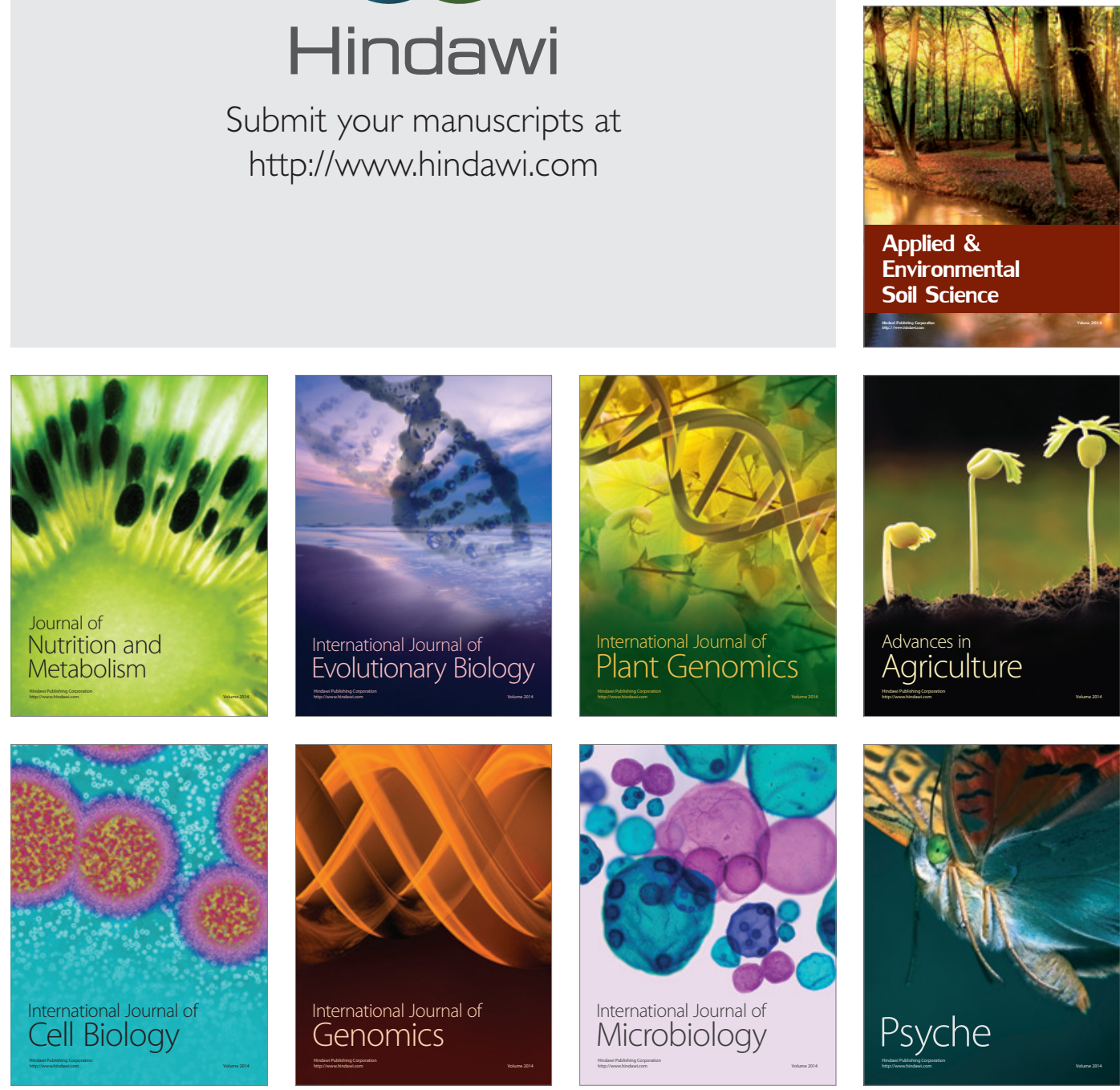
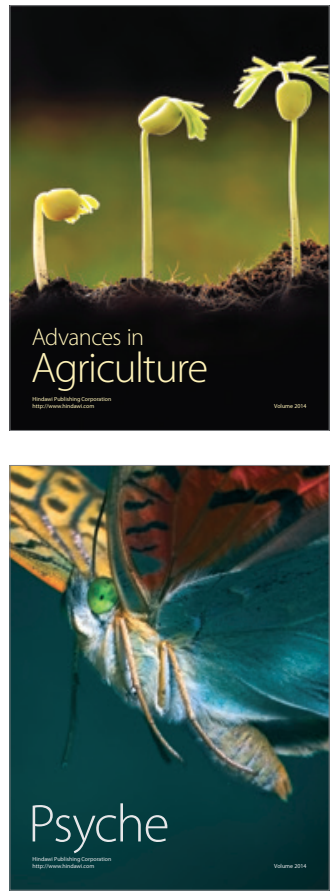